\title{
Relationships of International Students' L2 Vocabulary, Receptive Skills, and Strategy Use: A Pathway College Context
}

\author{
Tasnima Aktar ${ }^{1} \&$ Dina Strong ${ }^{2}$ \\ ${ }^{1}$ Comilla University, Bangladesh \\ ${ }^{2}$ Birkbeck, University of London, England \\ Correspondence: Tasnima Aktar, Comilla University, Bangladesh.
}

Received: July 6, 2019 Accepted: September 15, 2019 Online Published: September 17, 2019

doi: 10.5539/elt.v12n10p65 URL: https://doi.org/10.5539/elt.v12n10p65

\begin{abstract}
A considerable amount of studies has been done on the relationship of L2 vocabulary and reading/listening, strategy use and reading/listening, and vocabulary and strategy use in different contexts among different levels of learners; however, little has been known about the relationships among all these variables with the same cohort of learners and particularly with international students including Asian students in a UK pathway college context. Furthermore, existing research on these relationships is inconclusive. This paucity and inconclusiveness invoke this attempt to understand the relationships of all these variables among pre-sessional international students. Quantitative data were collected from 31 Pre-Undergraduate (PU) and Pre-Masters (PM) international students via Strategy Inventory of Language Learning (SILL; Oxford, 1990), IELTS-style reading and listening tests, and an academic vocabulary test designed from Quizlet for class test. Results showed that there was no significant relation of vocabulary with reading and listening among the whole cohort of students and the PU group; however, there was a significant relationship between reading and listening among the whole cohort and the PU group. Among the PM group only, significant relationship was seen between vocabulary and reading. Social strategy category and some individual strategies were significantly correlated with reading among the whole cohort, and the significant correlation of social strategy category and reading was also true for the PM group. While memory strategies were significantly, positively correlated with vocabulary among the PM group, affective strategies were negatively correlated vocabulary among the PU group. Independent sample t-test revealed significant difference between the PM and PU groups on their vocabulary knowledge. Although the pattern of the relationships revealed was not always clear among these diverse international students, the findings could inform teaching L2 receptive skills with regards to vocabulary and strategies, with a view to facilitate learning of English as an L2 in a target language context.
\end{abstract}

Keywords: L2 vocabulary, L2 receptive skills, strategy use, international students, a pathway college

\section{Introduction}

Both L2 vocabulary and strategy knowledge are well-known to have potentials to facilitate L2 learning. One the one hand, L2 vocabulary is fundamental to second language learners; knowledge of the words in a given sample of speech or writing strongly facilitates comprehension (Cheng \& Matthews, 2018; Nation, 2006). This link between vocabulary knowledge and L2 reading and listening performance (see Cheng \& Matthews, 2018; Stahr, 2009,2008 ) highlights the importance of vocabulary knowledge in order to cope with the linguistic demands of these fundamental L2 skills (Cheng \& Matthews, 2018; Nation, 2001). Vocabulary is considered as one of the key components of language learning which is the foundation of effective learning of listening, speaking and writing (Richards \& Renandya, 2002); therefore, deficiencies in vocabulary may affect learners' communication skills (Nation, 2001). On the other hand, the instrumental role of language learning strategies (LLSs) is well accepted (Oxford, 1990; O’Malley \& Chamot, 1990; Graham, Santos, \& Vanderplank, 2008; Vandergrift \& Goh, 2012). While O'Malley and Chamot (1990) define learning strategies as "special thoughts or behaviours that individuals use to help them comprehend, learn, or retain new information" (p. 1), Oxford's (1990) defined that “...learning strategies are operations employed by the learner to make learning easier, faster, more enjoyable, more self-directed, more effective, and more transferable to new situations" (p. 8).

Different factors contribute to different language skills in different settings differently. Increased engagement with, and use of a given word, is strongly associated with a learner's knowledge of that word (Ellis, 2002) and 
with increased frequency of exposure comes increased richness of representation in the learner's mental lexicon, which in turn is important for a learner to attain productive control over a given word (Henriksen, 1999). Orthographic vocabulary knowledge has a strong relationship with both reading and listening (Stahr, 2008). Studies also suggest a positive link between strategy use and reading comprehension and thus reading strategies may have the potential to enhance learners' reading comprehension (e.g., Carrell, 1989; Zhang, 2002). Again, L2 listeners often find it hard to understand native English speakers and use different strategies to process the txt and comprehend (Goh, 2000). As postulated by Wang and Treffers-Daller (2017, p.1), listening comprehension "constitutes a major problem for second language learners but little is known about the relative contribution of different factors to listening comprehension". Therefore, to further investigate the influence of different factors such as vocabulary and strategy use on L2 receptive skills and the relationships among them, the present study attempted to explore a multinational and multicultural group of international students with different L1s in an L2 setting. Among the number of dimensions of word knowledge outlined in Nation's (2001) taxonomy, the current study looked into orthographical words and among the four macro-language skills, the present study explored receptive skills only.

\section{Relevant Literature and Context}

Among the existing literature, some studies show a significant positive relationship between vocabulary and reading (e.g., Li \& Kirby, 2015; Qian, 2002) and vocabulary and listening (e.g., Bonk, 2000; Kelly, 1991; Stahr, 2009), some others between strategy use and reading (e.g., Zhang, 2002) and strategy use and listening (e.g., Goh \& Hu, 2014; Vandergrift, Goh, Mareschal, \& Tafaghodtari, 2006). There are also studies showing a positive correlation between vocabulary and strategy use (e.g., Gu \& Johnson, 1996; Teng, 2015; Wei, 2007). However, there are some studies e.g., Amirian, Mallahi, and Zaghi (2015), Serri, Boroujeni, and Hesabi (2012) that did not show that significant relationships, therefore existing results are mixed. More importantly, very few studies have looked into all these relationships among the same cohort of learners, particularly international learners with different backgrounds.

\subsection{Vocabulary and Receptive Skills}

Numerous studies have investigated the relationship between vocabulary knowledge and any of the receptive skills; however, research exploring both the receptive skills is limited. While Qian (2002) and Li and Kirby (2015) investigated the relationship with reading skill, Stahr (2009) and Matthews and Cheng (2015) explored that with listening skill. Qian (2002) explored the relationship between reading and vocabulary knowledge among 217 English as a second language (ESL) students with different L1 including Korean, Japanese, Spanish, Chinese, Arabic, Russian and so on. The study found a strong and significant correlation between vocabulary depth and reading comprehension $(r=.77, p<.01)$ and vocabulary breadth and reading comprehension $(r=.74$, $p<.01)$. Li and Kirby (2015) investigated the relationship between vocabulary knowledge and reading comprehension among 246 Chinese school students learning English and found a positive and in the most part statistically significant correlations. On the other hand, Stahr (2009) explored the relationship between vocabulary knowledge and listening comprehension of 115 advanced Danish EFL learners and found a strong and significant relationship between receptive, orthographic vocabulary size and listening comprehension. Matthews and Cheng (2015) investigated the strength of association between knowledge of high-frequency L2 words and L2 listening comprehension among 167 native Chinese students and found a strong correlation $(r$ $=.73, p<.05)$.

Bonk (2000) and Kelly (1991) investigated lexical knowledge and listening proficiency. Bonk (2000) investigated the interaction between lexical knowledge and listening comprehension in a second language among 59 Japanese university students of different English abilities and learners of high, middle, or low second-language listening proficiency. Comprehension correlated with lexis familiarity and concluded that efficient listening strategies might make comprehending lexically complex texts possible but most learners seemed to need very high lexical familiarity for good comprehension. In line with Bonk (2000), Kelly (1991) claimed that lexical ignorance is the major obstacle to listening comprehension among L2 learners. Kelly found that $42 \%$ of the errors in transcription among high-proficiency subjects and $63 \%$ of those of low-proficiency subjects were apparently due to ignorance of the lexical items in question and suggested that their efforts would be better spent increasing their knowledge of the L2 (e.g., vocabulary and grammar), and especially their ability to recognize these words in their natural spoken style.

Existing literature looked into the relationship between L2 vocabulary knowledge and the skills of L2 listening (Matthews \& Cheng, 2015; Stahr, 2009) and L2 reading (Li \& Kirby, 2015; Qian, 2002); however, research exploring both of the receptive skills with vocabulary with a single cohort of L2 learners is only few (e.g., Cheng 
\& Matthews, 2018; Stahr, 2008). Stahr (2008) investigated the strength of association between the L2 vocabulary knowledge of 88 Danish EFL students and their L2 listening and reading comprehension. Cheng and Mathews (2018) explored the strengths of association between three different measures of vocabulary knowledge and the measures of second language (L2) listening and reading among 250 tertiary-level Chinese learners of English as a foreign language (EFL). Regression modelling showed that productive, phonological vocabulary knowledge explained $51 \%$ of the variance in L2 listening scores and that productive, orthographical vocabulary knowledge explained $33 \%$ of the variance in the $\mathrm{L} 2$ reading scores.

\subsection{Strategy Use and Receptive Skills}

Skilled listeners and readers not only reply on language knowledge e.g., vocabulary, they also integrate contextual knowledge and general knowledge about the world into their understanding of speech or writing (Wang \& Treffers-Daller, 2017). Learners focusing too much on decoding the incoming speech signal "deprive themselves of the opportunity to compensate for lack of linguistic knowledge through the use of cognitive and metacognitive strategies" (Stahr, 2009, p. 581).

Studies e.g., Teng (1998), Liu (2008), and Serri et al. (2012) investigated relationship between EFL students' strategy use and listening comprehension using differently developed listening strategy questionnaire and Vandergrift et.al. (2006) and Goh and Hu (2014) explored the relationship between metacognitive awareness including strategy use and listening comprehension using Metacognitive Awareness Listening Questionnaire (MALQ, Vandergrift et al., 2006).

The results of the relationship are mixed. Teng (1998) investigated the EFL listening comprehension strategies used by 51university students with a strategy questionnaire of Oxford's (1990) SILL and found that compensation techniques were most often used by the students, followed by cognitive strategies, and then metacognitive strategies. T-test indicated that effective listeners used significantly more strategies than ineffective listeners did in five of the six categories- memory, cognitive, compensation, metacognitive, and social; affective category did not reach significance. Liu (2008) among a sample of 101 Taiwanese university EFL students via a questionnaire of listening strategy use from O'Malley et al. (1985) and Vandergrift 1997 reported that there was a statistically significant difference between the strategy use and the attainment levels at the $p<.05$ level. However, the significance was not consistent among the groups e.g., in the metacognitive strategies, advanced learners and lower intermediate learners differed significantly from one another, but not from upper intermediate learners. Wang and Treffers-Daller (2017) studied, among 151 non-English major university students in China, what proportion of the variance in listening comprehension was explained by general language proficiency, vocabulary size and metacognitive awareness. The results showed that vocabulary size was the strongest predictor followed by general language proficiency and metacognitive awareness was less important. However, Serri et al. (2012) investigated the relationship among 40 Iranian university EFL students using strategy questionnaire adapted from Vandergrift (1997) and an IELTS listening test and the results reached no significant correlation between use of the strategy categories and listening performance.

Using MALQ, Vandergrift et al (2006) and Goh and Hu (2014) showed a significant and positive correlation between metacognitive awareness and strategy use in ESL contexts. In Vandergrift et al. (2006), the correlation coefficient was $\mathrm{r}=.36$ at $\mathrm{p}<.001$ level and indicated that $13 \%$ of the variance in the participants' listening performance could be explained by their awareness of the L2 listening processes and strategies. Goh and $\mathrm{Hu}$ (2014) revealed $22 \%$ of the variance in listening performance due to metacognitive knowledge. Analysis of individual factors showed a significant relationship between listening performance and the strategies of directed attention and problem solving.

Studies on strategy use and reading comprehension also show some positive relationship between them. Aktar and Ahmed (2018), Carrell (1989), and Zhang (2002) investigated metacognitive awareness of strategy use and reading and found a relation between strategy awareness and reading comprehension. Using Metacognitive Awareness Strategy Questionnaire (MASQ) developed by herself Carrell (1989) explored four aspects of strategy use- confidence, difficulty, repair, and effectiveness and revealed that learners' metacognitive awareness, particularly metacognitive awareness of difficulty and effectiveness were related to their reading proficiency and higher proficiency readers tended to be more global and using top-down processes in L2 reading. Aktar and Ahmed (2018) explored Bangladeshi higher secondary-level EFL learners' metacognitive awareness of strategy use in EFL reading comprehension among 148 higher secondary-level EFL learners via a modified Metacognitive Awareness Strategy Questionnaire (MASQ; Carrell, 1989) and found that learners possessed moderate awareness of reading strategies and their perceptions of effective strategies and of difficulty of strategy use are significantly and positively related to their reading comprehension. 


\subsection{Strategy Use and Vocabulary}

Studies explored the influence of vocabulary and strategy use separately on L2 receptive skills; however, what is the relationship between vocabulary and strategies also intrigued researchers. Some studies tried to see the relationship between vocabulary learning strategies and vocabulary size and language proficiency. Gu and Johnson (1996) and Teng (2015) adapted Oxford's (1990) SILL in the case of vocabulary. Gu and Johnson (1996) aimed to establish the relationship between the vocabulary learning strategies and outcomes in learning English among 850 Chinese university learners and found self-initiation and selective attention-two metacognitive strategies as positive predictors of English. Contextual guessing, skilful use of dictionaries, notetaking, paying attention to word formation, contextual encoding, and activation of newly learned words also positively correlated with the two test scores. However, visual repetition of new words and memorisation were negatively correlated with both vocabulary size and general proficiency. Following Gu and Johnson (1996), Teng (2015) explored 145 low proficiency EFL students and found that EFL students' strategy use was correlated significantly and positively with breadth and depth of vocabulary knowledge. Indirect strategy use had a higher level of correlation with two dimensions of vocabulary knowledge which highlighted the importance of indirect strategies, e.g., self-planning, self-monitoring, and self-evaluating. Wei's (2007) investigated 60 tertiary-level Chinese students on their vocabulary learning strategy use and their self-rated English proficiency and found that English majors frequently used more vocabulary learning strategies than non-English majors and the students with higher English proficiencies used more vocabulary learning strategies than those with lower English proficiencies.

However, some studies did not find any significant correlations between strategy use and vocabulary. Amirian, Mallahi, and Zaghi (2015) explored self-regulation and vocabulary size. The results revealed no significant relationship between the two variables except multiple regressions indicated that the metacognitive control compared to the other subscales might predict learners' vocabulary size. However, the study also compared the self-regulatory strategy use of learners in different experience groups and found the first year students had a higher mean score in their self-regulation capacity, which could explain the strategies they had learnt in their Study Skills courses.

\subsection{Context}

The literature reviewed above looked into different ESL and EFL contexts with different L1s; however, studies looking into all the above-mentioned variables with a single cohort of study- abroad learners possessing various different L1s and cultural backgrounds are limited. The present study aimed to explore international students who came to study abroad and enrolled at an international pathway college in the UK. These students come from different parts of the globe such as South America, Europe, Africa, Middle East, and Asia including China, Korea, India, Pakistan, and even Bangladesh. Their end goal is university admission for different undergraduate, Masters, and $\mathrm{PhD}$ programmes at different UK universities upon successful completion of their accredited programmes on their respective majors of science and engineering, business, and social sciences. The population of the current study consists of pre-undergraduate (PU) and pre-Masters students (PM) in a summer term. Before coming to the UK, almost all the students had already sat for IELTS and their scores range from 5.5 to 8 . Irrespective of their scores, these PU and PM students were entitled to complete some English language courses one of which compulsory for all PU and PM students as part of their programmes at this international pathway college; the partner universities accept the scores of this language module of 13 weeks as equivalent to IELTS and it encompasses four skills, assessment of which is similar to high stake examination IELTS. As a foundation to four macro-skills, students are also expected to study academic vocabulary from online quizlet and sit for class test each week. Although both the groups took same language module with same curriculum, teacher, etc., differences between the PU and PM groups are huge in terms of their age and formal English learning exposure and experience from their home countries. Therefore, the context of the present study is different form contexts of other studies and merits investigation.

\subsection{Research Questions}

Building on the existing body of research and based on the gaps revealed, this study attempted to investigate the relationships of vocabulary knowledge, receptive skills, and strategy use. To this end, the study formulated following four research questions:

1). Is there any relationship between vocabulary knowledge and performance in listening and reading in a pathway college context?

2). Is there any relationship between strategy use and performance in listening and reading? 
3). What is the relationship between strategy use and vocabulary knowledge?

4). Are there any differences between Pre-Undergraduate and Pre-Masters students on their vocabulary knowledge, performance in listening and reading, and strategy use?

\section{Methods}

\subsection{Participants}

The population of this study are international students pursuing their credited pre-undergraduate and pre-Masters programmes at an international pathway college in the UK with an aim to be enrolled at undergraduate or Masters programmes at different UK partner universities next academic year. 31 students, 15 Pre-Undergraduate and 16 Pre-Masters students, participated voluntarily in this study. Before the time of data collection, all the students had at least one more term at this college and had to take other language courses.

\subsection{Data Collection Tools}

Four data collection tools were exploited. The students took academic listening and reading test, and vocabulary test as baseline tests in the classroom in the beginning of the module. On the other hand, their perceptions of Language Learning Strategies (LLSs) were elicited via Strategy Inventory of Language Learning (SILL), Version 7.0 (ESL/EFL) questionnaire with Likert-scale developed by Oxford (1990). SILL is widely used and validated in different contexts across the globe to elicit strategy data on second/foreign language learning including the four skills. While the listening and reading tests were sample high-stake tests equivalent to IELTS, vocabulary test was designed to observe students' progress with frequently occurring academic words from an online quizlet while continuing the module. Each of the listening and reading tests carries 45 discrete marks against 45 questions, and vocabulary test carries 50 marks.

\subsection{Data Analysis}

Quantitative data collected via the above tools were analysed quantitively. Students performance in the language item tests were marked objectively using the answer keys provided with the sample tests for the module. All raw data of language tests and strategy questionnaire were inputted into SPSS and data were then analysed using descripting statistics and inferential statistics of correlations and independent sample t-tests.

\section{Results}

\subsection{Research Question 1}

Descriptive statistics (see Table 1 below) of the students' vocabulary and receptive skills scores showed they scored $70.64 \%$ (35.32 out of 50) in vocabulary, $75.20 \%$ (33.84 out of 45 ) in listening and $65.89 \%$ (29.65 out of 45 ) in reading, which also revealed their better performance in listening than reading.

Table 1. Mean of vocabulary and receptive skills

\section{Descriptive Statistics}

\begin{tabular}{llll} 
& Mean & Std. Deviation & N \\
\hline Vocabulary & 35.32 & 5.67 & 31 \\
Listening & 33.84 & 5.66 & 31 \\
Reading & 29.65 & 5.06 & 31 \\
\hline
\end{tabular}

Pearson correlations computed between the students' vocabulary and receptive skills (see Table 2 below) revealed no significant correlations between vocabulary and either of the receptive skills; however, the results showed a strong correlation $(\mathrm{r}=.736, \mathrm{p}=000)$ between their listening and reading scores. This indicated a strong, positive relationship between their listening and reading comprehension.

Table 2. Correlations between vocabulary and receptive skills

\section{Correlations}

\begin{tabular}{|c|c|c|c|c|}
\hline & & Vocabulary & Listening & Reading \\
\hline Vocabulary & Pearson Correlation & 1 & .183 & .309 \\
\hline
\end{tabular}




\begin{tabular}{lllll}
\hline \multirow{4}{*}{ Listening } & Sig. (2-tailed) & & .324 & .091 \\
& $\mathrm{~N}$ & 31 & 31 & 31 \\
& Pearson Correlation & .183 & 1 & $.736^{* *}$ \\
& Sig. (2-tailed) & .324 & & .000 \\
Reading & $\mathrm{N}$ & 31 & 31 & 31 \\
& Pearson Correlation & .309 & $.736^{* *}$ & 1 \\
& Sig. (2-tailed) & .091 & .000 & \\
& $\mathrm{~N}$ & 31 & 31 & 31 \\
\hline
\end{tabular}

**. Correlation is significant at the 0.01 level (2-tailed).

\subsection{Research Question 2}

Descriptive statistics of the students' perceptions of LLSs showed that they used strategies moderately $(M=3.21$, $\mathrm{SD}=.53$ ). They perceived that they used social, compensation, metacognitive strategies moderately but more frequently than they used affective and memory strategies which were of less frequently use.

Table 3. Mean of language learning strategies

\section{Descriptive Statistics}

\begin{tabular}{llll} 
& Mean & Std. Deviation & N \\
\hline Memory & 2.83 & .61 & 31 \\
Cognitive & 3.32 & .66 & 31 \\
Compensation & 3.39 & .73 & 31 \\
Metacognitive & 3.33 & .75 & 31 \\
Affective & 2.92 & .66 & 31 \\
Social & 3.41 & .84 & 31 \\
Overall Strategy & 3.21 & .53 & 31
\end{tabular}

Pearson correlations computed between overall LLSs and strategy categories and receptive skills exhibited that only social strategies are moderately correlated with reading comprehension $(r=.429, p=.016)$. These results indicated that not all strategies were significantly correlated with students' language performance i.e., listening and reading.

Table 4. Correlations between overall strategies, strategy categories and receptive skills

\begin{tabular}{llll}
\hline Strategy category & & Listening & Reading \\
\hline \multirow{2}{*}{ Memory } & Pearson Correlation & .023 & .183 \\
& Sig. (2-tailed) & .902 & .324 \\
& $\mathrm{~N}$ & 31 & 31 \\
Cognitive & Pearson Correlation & .002 & .237 \\
& Sig. (2-tailed) & .991 & .198 \\
& $\mathrm{~N}$ & 31 & 31 \\
Compensation & Pearson Correlation & -.111 & .240 \\
& Sig. (2-tailed) & .553 & .194 \\
\hline
\end{tabular}


N

$$
\text { Pearson Correlation }
$$

Metacognitive

Sig. (2-tailed)

$\mathrm{N}$

Pearson Correlation

Affective

Social

Overall Strategy
Sig. (2-tailed)

$\mathrm{N}$

Pearson Correlation

Sig. (2-tailed)

$\mathrm{N}$

Pearson Correlation

Sig. (2-tailed)

$\mathrm{N}$
31

$-.195$

$-.030$

.293

.875

31

$-.232$

.103

.210

.581

31

31

.134

$.429^{*}$

.472

.016

31

31

$-.070$

.707

.167

31

*. Correlation is significant at the 0.05 level (2-tailed).

Pearson correlations computed between individual strategy use and receptive skills exhibited that some of the strategies were significantly correlated with listening and or reading skills (see Table 5 below). While thinking of relationship between new words and prior knowledge (1, memory) and using gestures when thinking of a new word during a conversation (25, compensation) is positively correlated with the students' reading comprehension, practising English with other students (47, social) is positively correlated with both listening and reading skills.

Table 5. Correlations between individual strategy items and receptive skills

\begin{tabular}{|c|c|c|c|}
\hline \multirow[t]{2}{*}{ Individual Strategy } & & Listening & Reading \\
\hline & Pearson Correlation & & $.380^{*}$ \\
\hline \multirow[t]{2}{*}{1} & Sig. (2-tailed) & & .035 \\
\hline & $\mathrm{N}$ & & 31 \\
\hline \multirow{3}{*}{25} & Pearson Correlation & & $.436^{*}$ \\
\hline & Sig. (2-tailed) & & .014 \\
\hline & $\mathrm{N}$ & & 31 \\
\hline \multirow{3}{*}{47} & Pearson Correlation & $.436^{*}$ & $.525 * *$ \\
\hline & Sig. (2-tailed) & .014 & .002 \\
\hline & $\mathrm{N}$ & 31 & 31 \\
\hline
\end{tabular}

*. Correlation is significant at the 0.05 level (2-tailed).

**. Correlation is significant at the 0.01 level (2-tailed).

1-I think of relationship between what I already know and new things I learn in English.

25-When I can't think of a word during a conversation in English, I use gestures.

47-I practise English with other students. 


\subsection{Research Question 3}

These results indicated that none of the strategy categories or overall strategies was significantly correlated with students' vocabulary.

Table 6. Correlations between overall strategies, strategy categories and vocabulary

\begin{tabular}{|c|c|c|}
\hline Strategy categories & & Vocabulary \\
\hline \multirow{3}{*}{ Memory } & Pearson Correlation & .304 \\
\hline & Sig. (2-tailed) & .097 \\
\hline & $\mathrm{N}$ & 31 \\
\hline \multirow{3}{*}{ Cognitive } & Pearson Correlation & .249 \\
\hline & Sig. (2-tailed) & .178 \\
\hline & $\mathrm{N}$ & 31 \\
\hline \multirow{3}{*}{ Compensation } & Pearson Correlation & .302 \\
\hline & Sig. (2-tailed) & .099 \\
\hline & $\mathrm{N}$ & 31 \\
\hline \multirow{3}{*}{ Metacognitive } & Pearson Correlation & .100 \\
\hline & Sig. (2-tailed) & .591 \\
\hline & $\mathrm{N}$ & 31 \\
\hline \multirow{3}{*}{ Affective } & Pearson Correlation & -.082 \\
\hline & Sig. (2-tailed) & .661 \\
\hline & $\mathrm{N}$ & 31 \\
\hline \multirow{3}{*}{ Social } & Pearson Correlation & .126 \\
\hline & Sig. (2-tailed) & .501 \\
\hline & $\mathrm{N}$ & 31 \\
\hline \multirow{3}{*}{ Overall Strategy } & Pearson Correlation & .242 \\
\hline & Sig. (2-tailed) & .190 \\
\hline & $\mathrm{N}$ & 31 \\
\hline
\end{tabular}

*. Correlation is significant at the 0.05 level (2-tailed).

Pearson correlations computed between individual strategy use and vocabulary exhibited that some of the strategies were significantly correlated with vocabulary (see Table 7 below). Using new English words in a sentence to remember them (2), connecting the sound of a new English word and an image of it to help remember (3), talking like native English speakers (11), and using a synonym of unknown word or phrase (29) were positively correlated with the students' vocabulary knowledge. 
Table 7. Correlations between individual strategy items and vocabulary

\begin{tabular}{lll}
\hline Individual Strategy & & Vocabulary \\
\hline & Pearson Correlation & $.358^{*}$ \\
& Sig. (2-tailed) & .048 \\
$\mathrm{~N}$ & 31 \\
& & $.448^{*}$ \\
& Pearson Correlation & .012 \\
& Sig. (2-tailed) & 31 \\
& $\mathrm{~N}$ & $.368^{*}$ \\
11 & Pearson Correlation & .042 \\
& Sig. (2-tailed) & 31 \\
& $\mathrm{~N}$ & $.392^{*}$ \\
& & .029 \\
& Pearson Correlation & 31 \\
\hline
\end{tabular}

*. Correlation is significant at the 0.05 level (2-tailed).

**. Correlation is significant at the 0.01 level (2-tailed).

2-I use new English words in a sentence so I can remember them.

3-I connect the sound of a new English word and an image or picture of the word to help me remember the word.

11-I try to talk like native English speakers.

29-If I can't think of an English word, I use a word or phrase that means the same thing.

\subsection{Research Question 4}

To see the differences, if any, between two levels of students, namely Pre-Undergraduate students and Pre-Masters students, mean of language items and strategies, independent sample t-tests, group-wise Pearson correlations between strategy use and language items were calculated. The findings showed some important differences between the groups.

The findings from the Table 8 below show that although the mean of vocabulary among the PM group ( $M=37.75$, $\mathrm{SD}=4.95)$ is higher than that of their counterpart $(\mathrm{M}=32.73, \mathrm{SD}=5.34)$, the mean of both listening and reading is slightly higher among the PU group, as seen in Figure 1). 


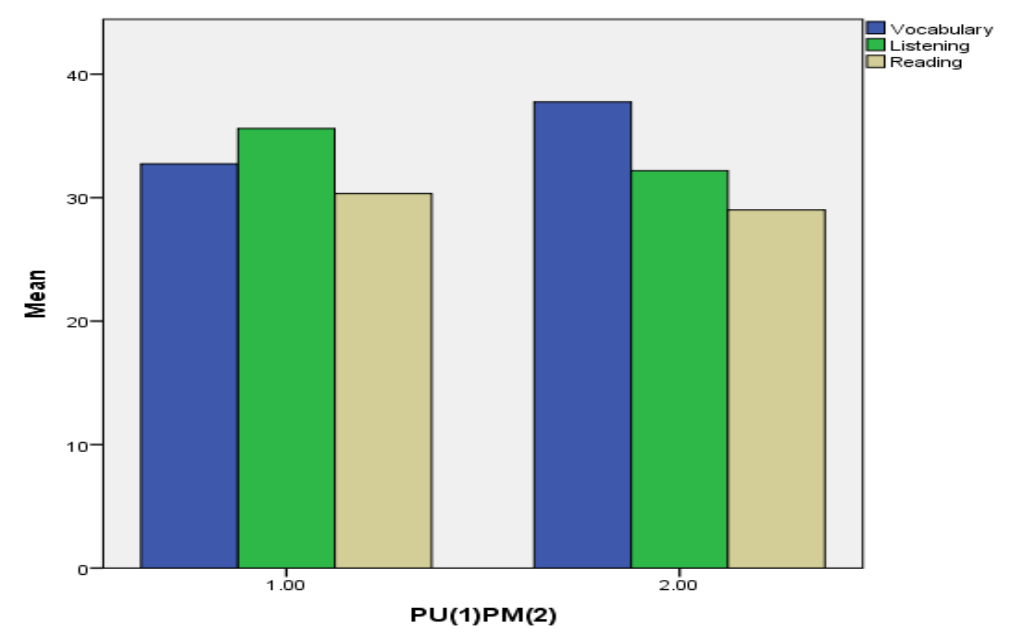

Figure 1. Vocabulary knowledge by UP and PM groups

Table 8. Mean of vocabulary, receptive skills and overall LLSs and strategy categories among the PU group and PM group

\begin{tabular}{|c|c|c|c|c|}
\hline & $\begin{array}{l}\text { Groups } \\
\text { PU (=1) } \\
\text { PM (=2) }\end{array}$ & $\mathrm{N}$ & Mean & Std. Deviation \\
\hline \multirow{2}{*}{ Vocabulary } & 1.00 & 15 & 32.73 & 5.34 \\
\hline & 2.00 & 16 & 37.75 & 4.97 \\
\hline \multirow{2}{*}{ Listening } & 1.00 & 15 & 35.60 & 5.19 \\
\hline & 2.00 & 16 & 32.19 & 5.74 \\
\hline \multirow{2}{*}{ Reading } & 1.00 & 15 & 30.33 & 5.04 \\
\hline & 2.00 & 16 & 29.00 & 5.15 \\
\hline \multirow{2}{*}{ Memory } & 1.00 & 15 & 2.86 & .46 \\
\hline & 2.00 & 16 & 2.81 & .75 \\
\hline \multirow{2}{*}{ Cognitive } & 1.00 & 15 & 3.29 & .66 \\
\hline & 2.00 & 16 & 3.34 & .67 \\
\hline \multirow{2}{*}{ Compensation } & 1.00 & 15 & 3.21 & .51 \\
\hline & 2.00 & 16 & 3.56 & .87 \\
\hline \multirow{2}{*}{ Metacognitive } & 1.00 & 15 & 3.24 & .76 \\
\hline & 2.00 & 16 & 3.42 & .76 \\
\hline \multirow{2}{*}{ Affective } & 1.00 & 15 & 2.85 & .78 \\
\hline & 2.00 & 16 & 2.98 & .54 \\
\hline \multirow{2}{*}{ Social } & 1.00 & 15 & 3.48 & .68 \\
\hline & 2.00 & 16 & 3.35 & .99 \\
\hline \multirow{2}{*}{ Overall Strategy } & 1.00 & 15 & 3.16 & .41 \\
\hline & 2.00 & 16 & 3.25 & .63 \\
\hline
\end{tabular}

*. Correlation is significant at the 0.05 level (2-tailed).

**. Correlation is significant at the 0.01 level (2-tailed).

Regarding strategies, the PM group showed slightly frequent use of overall strategies and many of the strategy 
categories- cognitive, compensation, metacognitive, affective strategies; however, the PU group revealed more use of memory and social strategies than their counterpart, also visualised in Figure 2 below.

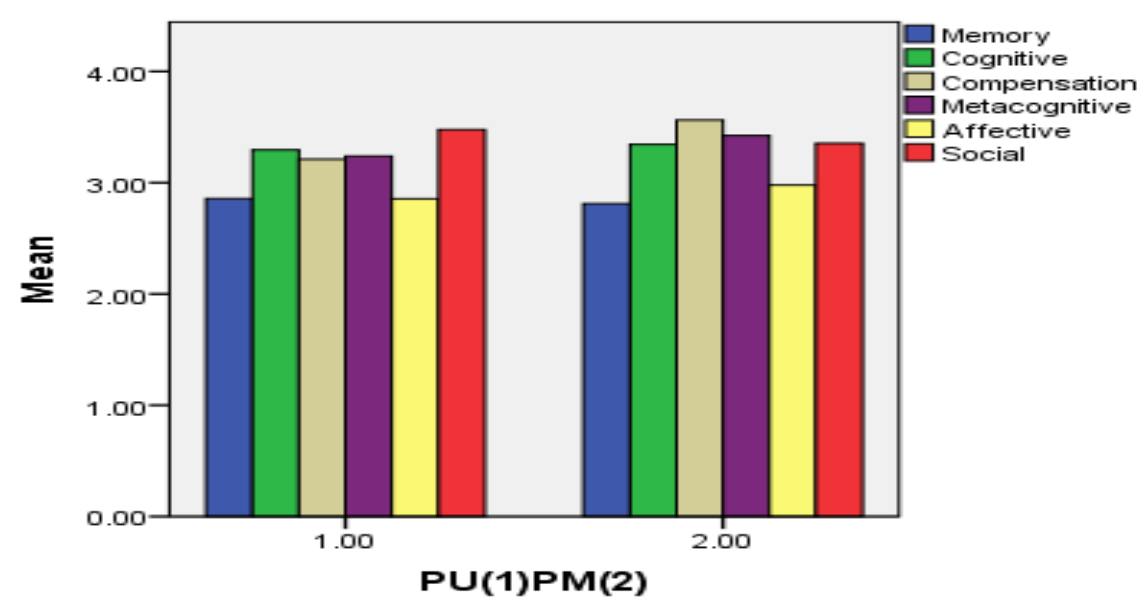

Figure 2. Use of strategy categories by the PU and PM groups

Independent sample t-test (see Table 9 below) showed significant group differences on vocabulary knowledge. There was a significant difference between UP group $(\mathrm{M}=32.73, \mathrm{SD}=5.34)$ and $\mathrm{PM}$ group $(\mathrm{M}=37.75, \mathrm{SD}=4.97)$ conditions; t $(29)=-2.75, p=.011$. Furthermore, the groups seemed to be not equal on their memory, compensation and social strategies but they also did not differ significantly.

Table 9. Independent sample t-test between PU and PM groups

\section{Independent Samples Test}

Levene's Test t-test for Equality of Means

for Equality

of Variances

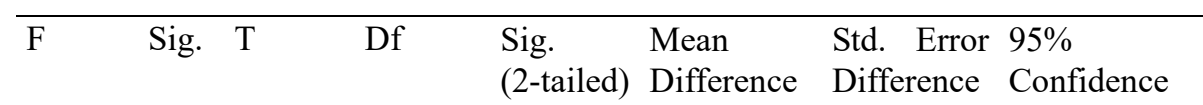

Lower Upper

Equal

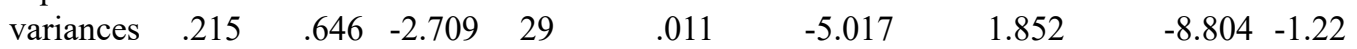

assumed

Vocabulary Equal

variances

not

assumed

Correlations were also computed groupwise to see the differences, if any, between the PU and PM groups, although it is acknowledged that the sample size is very small for correlations tests. As seen in the Table 10 below, the results showed that among the PU group, there was no correlation between vocabulary and receptive skills; however, reading is strongly correlated with listening. On the other hand, there was a negative but significant correlation between affective strategies and vocabulary knowledge. As seen in the Table 11 below, the results showed that there were significant positive correlations between vocabulary and reading and reading and listening but there was no significant correlation between vocabulary and listening. There were also significant, positive correlations between memory strategies and vocabulary, and social strategies and reading. 
Table 10. Correlations between LLSs and vocabulary and receptive skills among PU group

\begin{tabular}{llll}
\hline & & Vocabulary & Listening \\
\hline \multirow{3}{*}{ Reading } & Pearson Correlation & .248 & $.723^{* *}$ \\
& Sig. (2-tailed) & .373 & .002 \\
& $\mathrm{~N}$ & 15 & 15 \\
Affective & Pearson Correlation & $-.526^{*}$ & -.294 \\
& Sig. (2-tailed) & .044 & .288 \\
& $\mathrm{~N}$ & 15 & 15
\end{tabular}

*. Correlation is significant at the 0.05 level (2-tailed).

**. Correlation is significant at the 0.01 level (2-tailed).

Table 11. Correlations between LLSs and vocabulary and receptive skills among PM group

\begin{tabular}{lllll}
\hline & & Vocabulary & Listening & Reading \\
\hline \multirow{3}{*}{ Reading } & Pearson Correlation & $.583^{*}$ & $.748^{* *}$ & 1 \\
& Sig. (2-tailed) & .018 & .001 & \\
& $\mathrm{~N}$ & 16 & 16 & 16 \\
\multirow{3}{*}{ Memory } & Pearson Correlation & $.514^{*}$ & .252 & .478 \\
& Sig. (2-tailed) & .042 & .347 & .061 \\
& $\mathrm{~N}$ & 16 & 16 & 16 \\
Social & Pearson Correlation & .226 & .159 & $.520^{*}$ \\
& Sig. (2-tailed) & .399 & .556 & .039 \\
& $\mathrm{~N}$ & 16 & 16 & 16 \\
\hline
\end{tabular}

*. Correlation is significant at the 0.05 level (2-tailed).

**. Correlation is significant at the 0.01 level (2-tailed).

\section{Discussion}

Analyses of data elicited to address four research questions in the study revealed some key findings in terms of the relationship of vocabulary and receptive skills, that of strategy use and receptive skills, and strategy use and vocabulary, along with group differences on these relationships.

The findings revealed that the students' language proficiency was high on an average; they scored at least $65 \%$ in each of the language items/skills; however, their higher scores $(>70 \%)$ in vocabulary and listening indicated that they were comparatively less efficient in reading. The groups differ considerably on their vocabulary and slightly on their listening. Although PM group had higher vocabulary knowledge, it was the PU group who did better in listening. As revealed, the difference between the groups on their vocabulary knowledge is statistically significant. The PM students' more years of educational experience possibly contribute to their better vocabulary knowledge. However, unlike Cheng and Mathews (2018), the present study showed no significant relationship between vocabulary and receptive skills. That is, there was no significant impact of vocabulary on their receptive skills or vice versa. The present study was also in contrast with Chen and Mathews (2015), Stahr $(2009,2008)$ for listening, and Li and Kirby (2015), Stahr (2008), Qian (2002) for reading. This was also true for PU students, who with less vocabulary did comparatively better performance in listening and reading than their counterpart.

A strong, positive correlation between reading and listening performance, however, showed that they influenced each other i.e., a student's reading performance predicted their listening performance or vice versa, positively. This was also true groupwise; there was a significant relationship between listening and reading among the PU students as well as among the PU students separately. As vocabulary did not have any significant impact on overall students' or PU groups' any of the receptive skills, then some other confounding factors might interact in the relationship of reading and listening. It could be students' strategic competence or anything else. It can also be that once the students reach a threshold level of vocabulary knowledge, further vocabulary gaining might not 
have significant impact on their language processing and comprehension, particularly in receptive skills.

PM group, however, showed a more systematic pattern of their vocabulary knowledge and receptive skills. PM students showed a significant relationship between vocabulary and reading, which corroborated with Cheng and Mathews $(2018,2015)$ Stahr (2008). This relationship indicated that the influence of vocabulary knowledge was a better predictor for reading than listening, at least among the PM students. Mecartty (2000) and Nation (2006) contend that vocabulary knowledge influences learners' reading comprehension more than their listening comprehension. Stahr (2009) also opined that generally low correlation between vocabulary and listening can possibly be because comprehending spoken text demands heavily on the online processing system, therefore L2 learners rely on strategic competence more frequently during processing online text. Here, it, however, needs to acknowledge that the present study employed a vocabulary test which included orthographic vocabulary only. As revealed in Cheng and Mathews (2018), it was orthographical vocabulary which had a positive link with reading. In the case of listening, phonological vocabulary might predict listening performance, as seen in Cheng and Mathews (2018). As in listening which is transient in nature and not recursive like reading (Field, 2008), without phonological knowledge of the words the processing of and comprehending the incoming text is challenging (Goh, 2000).

As regards to strategy use, although the students used overall LLSs moderately, their use of memory and affective strategies was low, and they seemed to use social strategies more frequently. However, although highest use of social strategies was seen among the PU group, PM group use compensation strategies most frequently. The present study's L2 learning setting i.e., English country might be an influencing factor for the learners being more social in interacting and learning in groups and with peers. However, PM students' being more mature and a sense of detachment from foreign culture, more time spending in their home country might intimidate them to socialize more in a culturally different environment, and therefore they use social strategies less frequently than their counterpart in learning an L2. Rather they are keen to use more compensation strategies to comprehend and learn an L2. In fact, experience of study aboard and learning and performing in an L2 can be different from learner to learner due to a myriad of factors like age, years of learning experience in home culture, different L1 and so on.

Unlike previous studies e.g., Goh and Hu (2014), Liu (2008), Teng (1998), Vandergrift et al. (2006), the present study revealed no significant relationship between strategy use and listening. This non-significance, however, corroborates Serri et al. (2012). Liu (2008) also showed mixed findings when seen between the proficiency groups. The non-significance correlation between overall strategy use and reading is also in line with Aktar and Ahmed (2018), Zhang (2002), Carrell (1989). However, these previous studies showed a significant correlation of confidence and difficulty of strategies with reading comprehension. The present study, however, showed a significant, positive correlation between social strategies and reading. That is social strategies could predict reading performance. This implied that the students who cared to asked others when incomprehension happened and dared to be corrected if something went wrong, did better in their reading comprehension. These students also took practicing with peers or others and asking for help as positive. These students' fondness to learning English culture also served as integrative motivation for them to learn the English Language (see Gardner \& Lambert, 1972). This was also true for the PU students. Among individual strategies, students' finding a relation between new words and existing knowledge of them (a memory strategy), their compensation of lack of sufficient word knowledge by gesture (a compensation strategy) predicted their reading performance. The students' practising with peers and sharing ideas in a collaborative fashion (a social strategy) could predict their both receptive skills.

Now, the findings of non-significance between overall strategy use, its categories and vocabulary knowledge indicated that strategy might not influence their vocabulary knowledge. This finding contradicts some existing studies e.g., Teng (2015), Wei (2007) but corroborates with Amirian et al. (2015). However, some individual memory strategies and some cognitive and compensation strategies in the present study predicted their vocabulary knowledge. Unlike this study, Gu and Johnson (1996), however, showed a negative relation of some memory strategies with their vocabulary knowledge. Students' use of new words in a sentence and connecting the sound of a new word a to an image helped them remember and learn new vocabulary. The use of substitutions or synonyms also predicted their vocabulary knowledge. However, while the PM group's vocabulary knowledge was significantly and positively affected by their memory strategies, the PU groups' vocabulary was negatively affected by their affective strategies. That is, frequent use of memory strategies assisted in more vocabulary among the PM students but PU students who had less vocabulary used affective strategies more or vice versa. Teng (1998) also did not find any positive correlation between affective strategies and vocabulary knowledge. Overall, it seems, in the present study, that some memory and social strategies are 
better predictors of these students' vocabulary knowledge and reading performance in this present study.

\section{Conclusions and Recommendations}

There are some kinds of relationships between vocabulary and receptive skills and strategy use and receptive skills, and strategy use and vocabulary knowledge among the whole group of students or the groups separately, although the pattern is not always clear. As the groups differed significantly on their vocabulary knowledge, the groups seemed not to be equal. It is, however, dubious why PU students with less vocabulary knowledge did comparatively better in listening and reading, while their strategy use was also not significantly higher than their counterpart. More in-depth research studies on the relationships among such learner groups from different nationalities and cultural and linguistic backgrounds are needed. Moreover, the present study looked into orthographic word knowledge only, excluding phonological words which is an important dimension of vocabulary knowledge, particularly for listening (Cheng \& Mathews, 2018; 2015; Nation, 2001). Further studies on this is, therefore, called for, with various types of words necessary for reading and listening.

However, among such international students studying in a target language setting, social strategies might work better for target language learning. However, the pattern of the use of other strategies are mixed between the groups, hence more studies with larger sample size might produce further understanding of strategy use in relation to vocabulary knowledge and receptive skills. The present study thus acknowledges its small sample size. The study also suggests that future study may employ triangulation of strategy data tapped via different quantitative and qualitative measures as strategy questionnaire might not be a sensitive tool to tap into mental processes of strategy use (Aktar, 2017).

Overall, the present study has its merit in its investigation of international students in the UK and their linguistic and strategic behaviour while studying abroad and learning English as an L2 in the target language context. The complicated relationships between the target variables indicate the complex factors interacting in such situation with such cohort of learners. The study has, however, its significance in ascertaining some pattern in the relationship of strategy use and language items/skills and thus offers pedagogical implications. Based on the relationship between vocabulary and reading comprehension and that between reading and listening comprehension, instruction of vocabulary for reading and thus listening can be recommended for better language learning. And, some strategies' positive relations to vocabulary learning and to performance in receptive skills suggest instruction of language learning strategies for positive L2 learning.

\section{References}

Aktar, T. (2017). A Holistic Metacognitive Approach to EFL Listening and towards a Model of a 'Good'Listener: A Mixed-Methods Study (Doctoral Dissertation, University of York).

Aktar, T., \& Ahmed, I. (2018). Metacognitive Awareness of Strategy Use in EFL Reading Comprehension in Bangladesh. Journal of ELT Research, 204-221.

Amirian, S. M. R., Mallahi, O., \& Zaghi, D. (2015). The Relationship between Iranian EFL Learners' Self-Regulatory Vocabulary Strategy Use and Their Vocabulary Size. Iranian Journal of Language Teaching Research, 3(2), 29-46.

Bonk, W. (2000). Second language lexical knowledge and listening comprehension. International Journal of Listening, 14, 14-31.

Carrell, P. L. (1989). Metacognitive awareness and second language reading. The Modern Language Journal, 73(2), 121-134.

Cheng, J., \& Matthews, J. (2018). The relationship between three measures of L2 vocabulary knowledge and L2 listening and reading. Language Testing, 35(1), 3-25.

Ellis, N. C. (2002). Frequency effects in language processing: A review with implications for theories of implicit and explicit language acquisition. Studies in Second Language Acquisition, 24, 143-188.

Field, J. (2008). Listening in the language classroom. Cambridge: Cambridge University Press.

Gardner, R. C., \& Lambert, W. E. (1972). Attitudes and Motivation in Second-Language Learning. Rowly, Mass: Newbury House.

Goh, C. (2000). A cognitive perspective on language learners' listening comprehension problems. System, 28 , $55-75$.

Goh, C. C., \& Hu, G. (2014). Exploring the relationship between metacognitive awareness and listening performance with questionnaire data. Language Awareness, 23(3), 255-274. 
Graham, S., Santos, D., \& Vanderplank, R. (2008). Strategy clusters and sources of knowledge in French L2 listening comprehension. Innovation in Language Learning and Teaching, 4, 1-20.

Gu, Y. Q., \& Johnson, R. (1996). Vocabulary learning strategies and language outcomes. Language Learning, 46(4), 643-679.

Henriksen, B. (1999). Three dimensions of vocabulary development. Studies in Second Language Acquisition, 21, 303-317.

Kelly, P. (1991). Lexical ignorance: The main obstacle to listening comprehension with advanced foreign language learners. IRAL: International Review of Applied Linguistics in Language Teaching, 2, 135-149.

Li, M., \& Kirby, J. R. (2015). The effect of vocabulary breadth and depth on English reading. Applied Linguistics, $36,611-634$.

Liu, H. J. (2008). A study of the interrelationship between listening strategy use, listening proficiency levels, and learning style. Annual Review of Education, Communication \& Language Sciences, 5.

Mecartty, F. (2000). Lexical and grammatical knowledge in reading and listening comprehension by foreign language learners of Spanish. Applied Language Learning, 11, 323-348.

Matthews, J., \& Cheng, J. (2015). Recognition of high frequency words from speech as a predictor of L2 listening comprehension. System, 52, 1-13.

Nation, I. S. P. (2001). Learning vocabulary in another language. Cambridge, UK: Cambridge University Press.

Nation, I. S. P. (2006). How large a vocabulary is needed for reading and listening? Canadian Modern Language Review, 63(1), 59-81.

O’Malley, J. M, Chamot, A. U., Stewner-Manzanares, G., Russo, R. P., \& Kupper, L. (1985). Learning Strategy Applications with Students of English as a Second Language. TESOL Quarterly, 19, 557-584.

O’Malley, J. M., \& Chamot, A. U. (1990). Learning strategies in second language acquisition. Cambridge: Cambridge University Press.

Oxford, R. L. (1990). Language learning strategies. Cambridge: Cambridge University Press.

Qian, D. D. (2002). Investigating the relationship between vocabulary knowledge and academic reading performance: An assessment perspective. Language Learning, 52, 513-536.

Richards, J. C., \& Renandya, W. A. (Eds.). (2002). Methodology in language teaching: An anthology of current practice. Cambridge university press.

Serri, F., Boroujeni, A. J., \& Hesabi, A. (2012). Cognitive, metacognitive, and social/affective strategies in listening comprehension and their relationships with individual differences. Theory and Practice in Language Studies, 2(4), 843.

Stahr, L. (2008). Vocabulary size and the skills of listening, reading and writing. Language Learning Journal, 36, $139-152$.

Stahr, L. (2009). Vocabulary knowledge and advanced listening comprehension in English as a foreign language. Studies in Second Language Acquisition, 31, 577-607.

Teng, F. (2015). Assessing the Relationship between Vocabulary Learning Strategy Use and Vocabulary Knowledge. PASAA: Journal of Language Teaching and Learning in Thailand, 49, 39-65.

Teng, H. C. (1998). A Study of EFL Listening Comprehension Strategies. Paper presented at the Annual Convention and Exposition of the Teachers of English to Speakers of Other Languages, Seattle, WA.

Vandergrift, L. (1997). The comprehension strategies of second language (French) listeners: A descriptive study. Foreign Language Annals, 30, 387-409.

Vandergrift, L., \& Goh, C. (2012). Teaching and learning second language listening: Metacognition in action. New York: Routledge.

Vandergrift, L., Goh, C. C. M., Mareschal, C. J., \&Tafaghodtari, M. H. (2006). The metacognitive awareness listening questionnaire: Development and validation. Language Learning, 56, 431-462.

Wang, Y., \& Treffers-Daller, J. (2017). Explaining listening comprehension among L2 learners of English: The contribution of general language proficiency, vocabulary knowledge and metacognitive awareness. System, 65, 139-150. 
Wei, M. (2007). An examination of vocabulary learning of college levellearners of English in China. The Asian EFL Journal, 9(2), 93-114.

Zhang, L. J. (2002). Exploring EFL reading as a metacognitive experience: Reader awareness and reading performance. Asian Journal of English Language Teaching, 12, 69-94.

\section{Appendix}

\section{Strategy Inventory for Language Learning (SILL)}

Version 7.0 (ESL/EFL)- Oxford (1990)

Please tick the box under the number that is true of you. Do not answer how you think you should be or what other people do. There are no right or wrong answers to these statements.

1. Never or almost never true of me - means that the statement is very rarely true of you

2. Usually not true of me- means that the statement is true less than half the time

3. Sometime true of me- means that the statement is true of you about half the time

4. Usually true of me- means that the statement is true more than half the time

5. Always or almost always true of me- means that the statement is true of you almost always

\begin{tabular}{|c|c|c|}
\hline Serial no & Statements & 2 \\
\hline 1 & $\begin{array}{l}\text { I think of relationships between what I already know and new things I learn in } \\
\text { English. }\end{array}$ & \\
\hline 2 & I use new English words in a sentence so I can remember them. & \\
\hline 3 & $\begin{array}{l}\text { I connect the sound of a new English word and an image or picture of the word } \\
\text { to help me remember the word. }\end{array}$ & \\
\hline 4 & $\begin{array}{l}\text { I remember a new English word by making a mental picture of a situation in } \\
\text { which the word might be used. }\end{array}$ & \\
\hline 5 & I use rhymes to remember new English words. & \\
\hline 6 & I use flashcards to remember new English words. & \\
\hline 7 & I physically act out new English words. & \\
\hline 8 & I review English lessons often. & \\
\hline 9 & $\begin{array}{l}\text { I remember new English words or phrases by remembering their location on } \\
\text { the page, on the board, or on a street sign. }\end{array}$ & \\
\hline 10 & I say or write new English words several times. & \\
\hline 11 & I try to talk like native English speakers. & \\
\hline 12 & I practice the sounds of English. & \\
\hline 13 & I use the English words I know in different ways. & \\
\hline 14 & I start conversations in English. & \\
\hline 15 & I watch English language TV shows or go to movies spoken in English. & \\
\hline 16 & I read for pleasure in English. & \\
\hline 17 & I write notes, messages, letters, or reports in English. & \\
\hline 18 & I first skim an English passage (read it quickly) then go back and read carefully. & \\
\hline 19 & I look for words in my own language that are similar to new words in English. & \\
\hline 20 & I try to find patterns in English. & \\
\hline 21 & $\begin{array}{l}\text { I find the meaning of an English word by dividing it into parts that I } \\
\text { understand. }\end{array}$ & \\
\hline 22 & I try not to translate word-for-word. & \\
\hline
\end{tabular}


23 I make summaries of information that I hear or read in English.

24 To understand unfamiliar English words, I make guesses.

When I can't think of a word during a conversation in English, I use gestures.

I make up new words if I do not know the right ones in English.

I read English without looking up every new word

I try to guess what the other person will say next in English.

If I can't think of an English word, I use a word or phrase that means the same thing.

30 I try to find as many ways as I can to use my English.

I notice my English mistakes and use that information to help me do better.

I pay attention when someone is speaking English.

I try to find out how to be a better learner of English.

I plan my schedule so I will have enough time to study English.

35 I look for people I can talk to in English.

I look for opportunities to read as much as possible in English.

37 I have clear goals for improving my English skills.

38 I think about my progress in learning English

39 I try to relax whenever I feel afraid of using English.

40 I encourage myself to speak English even when I am afraid of making a mistake.

41 I give myself a reward or treat when I do well in English.

I notice if I am tense or nervous when I am studying or using English

43 I write down my feelings in a language learning diary.

44 I talk to someone else about how I feel when I am learning English.

45 If I do not understand something in English, I ask the other person to slow down or to say it again.

46 I ask English speakers to correct me when I talk.

$47 \quad$ I practice English with other students.

48 I ask for help from English speakers.

49 I ask questions in English.

50 I try to learn about the culture of English speakers.

\section{Copyrights}

Copyright for this article is retained by the author(s), with first publication rights granted to the journal.

This is an open-access article distributed under the terms and conditions of the Creative Commons Attribution license (http://creativecommons.org/licenses/by/4.0/). 